\title{
Cuerpos que (no) importan: Acerca de lo abyecto en la literatura chilena
}

\author{
Bodies that do (not) matter: \\ On the abject in Chilean literature
}

\author{
ANDREA KOTTOW
}

Universidad Adolfo Ibáñez

Correo electrónico: andrea.kottow@uai.cl

\begin{abstract}
Resumen
En las primeras décadas del siglo XX una serie de discursos articulan una crítica social y política dirigida a reformular la comunidad nacional chilena. Esta es evidenciada en tanto elitista y excluyente, generando un resto inadmitido de pobres y enfermos. Lo que se busca en este artículo es revisar la manera en que una serie de obras de comienzos del siglo XX configuran sus reivindicaciones sociales impulsando una discusión en torno a la comunidad con imágenes de aristas biopolíticas. A partir de los conceptos griegos de bios y zoé, retomados en forma central por los debates biopolíticos contemporáneos, este trabajo indaga en las maneras en que algunos textos plantean la necesidad de revisar las incisiones biopolíticas ejercidas sobre el cuerpo. Al mismo tiempo, se evidencian las contradicciones y tensiones que ostentan estos cambios en la concepción de la comunidad humana, nacional y ciudadana, mostrando de este modo las dificultosas maneras que adquiere la asunción de la modernidad en estas coordenadas.
\end{abstract}

Palabras clave: literatura chilena, comunidad, biopolítica, bios, zoé

Abstract

During the first decades of the 20th Century a series of discourses articulate a social and political critique in relation to the Chilean national community, denouncing its elitism and exclusion, always generating an inadmissible rest of poor and sick. The aim of this article is to study the approach with which a series of texts from the beginning of the 20th Century shape their social demands, promoting a discussion around the concept of community with bio-political images. Starting with the Greek notions of bios and zoé, which are picked up by contemporary bio political debates, this article explores the ways in which some texts raise the necessity of revising the bio political incisions upon the body. At the same time, the contradictions and tensions of these changes in the conception of human, national, and civil community show the difficult ways of assuming modernity in the Latin American context.

Key words: Chilean Literature, community, biopolitics, bios, zoe 


\section{Planteamientos introductorios:}

Toda comunidad solo puede pensarse desde el límite de algo que queda fuera de ella. Una comunidad implica la concepción de un común, de algo común, de algo en común. Desde la Antigüedad, es posible encontrar una serie de discursos filosóficos, políticos y literarios que giran en torno a la problemática de la comunidad. La historia de Occidente podría ser (d)escrita desde la perspectiva de cómo se han transformado las delimitaciones que hacen posible la configuración de determinadas comunidades, y en primerísimo lugar - pues posibilita la conceptualización en torno a la comunidad básica-, la de la humanidad. ¿Con relación a qué se diferencia el ser humano o lo humano? Luego, las interrogantes que apuntan a comprender diversas configuraciones de lo común: ¿Qué hace que unos seres humanos generen comunidad con otros? Comunidades nacionales y ciudadanas, comunidades religiosas, comunidades políticas e ideológicas. ¿Qué gestos políticos y/o simbólicos se ejecutan para dejar fuera de lo común a aquellos que no califican para formar parte de la comunidad planteada?

El siguiente artículo busca explorar ciertas mutaciones que ocurren en las primeras décadas del siglo XX en Chile con relación a la comunidad nacional, plasmadas discursiva y literariamente. Hacia finales del siglo XIX, se hace palpable una crisis que pareciera volver a hacer necesaria la pregunta por las condiciones de posibilidad de la comunidad, por quiénes la integran y cuáles son los requisitos para ello. Pero también, y cada vez con más insistencia, se abre paso la interrogante de la injusticia por la exclusión naturalizada que ejerce esta comunidad en su conformación. Lo que comienza a hacerse patente en textos a finales del siglo XIX, en las primeras décadas del siglo XX se cristaliza en tanto dominante en la escena política y literaria. La así llamada cuestión social gira desde sus diversas aristas en torno al problema de los excluidos de la comunidad y de sus privilegios ${ }^{1}$.

Una serie de textos literarios puede ser situada en este escenario, donde la literatura se vuelve crítica social, vehículo político de acusación y reclamación de justicia. Así se han leído dentro de la tradición literaria chilena las obras de autores que aparecen ligados a los movimientos naturalista y criollista, como Mariano Latorre, Marta Brunet, Baldomero Lillo, Joaquín Edwards Bello, o también con posterioridad, autores adscritos al neorrealismo, como Nicomedes Guzmán. Estas estéticas literarias precisamente han sido analizadas bajo el signo de su articulación respecto a una reclamación social que apunta a hacer ingresar al espacio letrado y cultural a actores sociales invisibilizados hasta ese momento para el mundo literario ${ }^{2}$. No es mi intención, en estos planteamientos, discutir las taxonomías

\footnotetext{
${ }^{1}$ Véase para una síntesis de las discusiones impulsadas por la "cuestión social”, el capítulo "La cuestión social y la corte de Versalles" incluido en el tercer tomo de la Historia de las ideas y de la cultura en Chile de Bernardo Subercaseaux (2004).

${ }^{2}$ El argumento desplegado por Horacio Legrás apunta justamente a destacar este rasgo de los movimientos naturalista y criollista: en la medida en que se propondría en sus literaturas, así Legrás, un grupo limitado de representaciones como característicos de la totalidad nacional, se cumple una función homogenizadora con respecto a la comunidad nacional que resulta central para el éxito del proyecto modernizante. El siglo XX trata
} 
que se han ocupado dentro de la historia de la literatura chilena ni para insistir en su pertinencia ni tampoco para señalar sus falencias, si bien me parece importante subrayar la necesidad de revisar las circunscripciones de movimientos y generaciones que tienden a anquilosar las lecturas y análisis de muchos textos del pasado. Sí quisiera plantear, y es ahí donde me interesa situar esta aproximación, que muchas veces en las obras literarias que proyectan una reivindicación social, lo que está simultáneamente en juego es una concepción de comunidad. En estas reconfiguraciones de lo común pueden hacerse palpable ciertos elementos de las obras que evidencian sus contradictorias maneras de constituir lo humano así como el cuerpo nacional. Quisiera así esbozar una lectura para algunos textos de las primeras dos décadas del siglo XX -algunos cuentos de Sub terra de Baldomero Lillo, publicado en 1904, un pequeño panfleto periodístico de Tancredo Pinochet de 1916, y la novela El roto de Joaquín Edwards Bello de 1920- para observar en ellos de qué forma debaten la problemática de la comunidad. En estas obras, así la propuesta, lo que estaría en cuestión es un desplazamiento de la concepción de la comunidad nacional a partir de un traslado de la incisión biopolítica que valida como vida relevante y valiosa ciertos cuerpos que caían fuera de la categoría de cuerpos que importan ${ }^{3}$. A partir de los conceptos griegos de bios y zoé, retomados por las discusiones biopolíticas contemporáneas, lo que se debate es la valoración de los cuerpos en tanto plataforma material del ser ciudadano. En los tres autores que revisaremos abundan las imágenes de una materialidad humana que se disuelve en la animalidad, impulsando un replanteamiento de la comunidad nacional en términos de lo humano. Entonces, lo que se jugaría en las obras a analizar son precisamente los límites de la comunidad, que amenaza con descomponerse en caso de no ser ampliado su radio, marcándose nuevos criterios de integración y exclusión, al mismo tiempo que en los textos se hacen palpables contradictorias maneras de dibujar lo común, evidenciando así una asunción fisurada del imaginario moderno.

Esta entrada analítica a los textos literarios trabajados aquí se pretende complementaria a otras formas en que han sido pensadas las transformaciones de la literatura en las primeras décadas del siglo XX. Desde la noción de subalternidad, puede ser comprendido a su vez el ingreso de personajes a la literatura antes marginados del espacio literario. La representación -entendida en la doble acepción acentuada por Spivak, en tanto representación estética pero también política- se vincula a la entrada de clases sociales

de producir una integración de todos los habitantes del territorio en un cuerpo nacional común. De esta forma, el criollismo busca la naturalización de las relaciones sociales que propone, construyendo la lengua, la tierra o la idiosincrasia como un destino. El criollismo se dirige al centro de la comunidad, ofreciendo imágenes de identificación e invita a sus lectores a sentirse reflejados en ellas (Véase, Legrás 2004).

${ }^{3}$ Tomo prestada la expresión de Judith Butler, que en su texto Cuerpos que importan (2015) vuelve sobre algunas reflexiones puestas en circulación en Género en disputa. Butler plantea desde el título una discusión acerca de la inteligibilidad de los cuerpos que se inscriben y son inscritos en y desde su materialidad en tanto cuerpos legibles y descifrables o, por el contario, se presentan como cuerpos que escapan a las normas de comprensión socialmente instituidas. Volveré sobre los alcances de los postulados de Judith Butler para el análisis propuesto acá más adelante en este trabajo. 
menos privilegiadas como actores culturales al campo intelectual. La literatura y la cultura dejan de estar en exclusivas manos de la elite política, económica y cultural de país, para abrirse a las clases medias. Es decir, las clases más desaventajadas se vuelven sujetos y objetos de la representación literaria. Esta mirada de corte más bien histórica, sin lugar a dudas es explicativa en gran medida de la transformación en el recorte de lo sensible, para retomar la expresión de Rancière, producido tras el cambio de siglo ${ }^{4}$.

$\mathrm{Al}$ adoptar una mirada centrada en las representaciones y la historia de la literatura, emergen el realismo y el naturalismo como los grandes momentos dentro de la tradición literaria que terminan por claudicar la separación de estilos exigida por el canon aristotélico. Toda la propuesta del filólogo Erich Auerbach en su célebre Mímesis gira en torno a la pregunta por la configuración de la realidad con la variedad de sus matices en el espacio literario. Serían precisamente los autores realistas y naturalistas -Auerbach ejemplifica este proceso con Stendhal, Balzac y Flaubert, así como con los hermanos Goncourt y Emile Zola- los que amplían el radio de aquello que se considera materia adecuada y pertinente para convertirse en literatura. No habría, a partir de estos autores del siglo XIX, nada a priori excluido de la obra literaria: ni por la pertenencia a una determinada clase social, ni por su supuesta banalidad, ni por atentar contra las normas de la moral y del buen gusto. Este quiebre, producido en la tradición literaria europea en el transcurso del siglo XIX, rompe con la separación de estilo, disputándosele a la comedia el espacio de lo considerado clásicamente "bajo". Lo que evidencia la mirada de Auerbach es que la representación de la realidad es sometida a cambios profundos con el realismo y el naturalismo, produciéndose el ingreso de personajes anteriormente marginados de la literatura.

La mirada biopolítica propuesta en este trabajo pone el acento en el tema de la comunidad vista bajo el prisma biopolítico, para reflexionar acerca de los modos en que los textos articulan lo común, justamente trazando nuevamente las líneas divisorias que separan lo propio de lo que no lo es, a partir de una serie de incisiones realizadas sobre los cuerpos. Me parece especialmente fructífera esta aproximación a los textos, pues permite entenderlos desde las contradictorias maneras en que se posicionan con relación a la pregunta por la comunidad. De este modo, las obras se consideran en su calidad de objetos estéticos, como también en tanto gestos políticos.

La configuración de los textos acá considerados -que reúne obras muy estudiadas por la crítica chilena, como la novela El roto de Edwards Bello y los clásicos cuentos de Baldomero Lillo, con textualidades menos prominentes, como la acusación de Tancredo Pinochet- pretende subrayar, desde la lectura biopolítica, la materialidad que subyace a la idea de comunidad. El roto ha sido analizada sobre todo como una novela urbana que hace

\footnotetext{
${ }^{4}$ La conocida expresión de Rancière es definida al comienzo de su ensayo homónimo como "ese sistema de evidencias sensibles que al mismo tiempo hace visible la existencia de un común y los recortes que allí definen los lugares y las partes respectivas. Un reparto de lo sensible fija entonces, al mismo tiempo un común repartido y partes exclusivas. Esta repartición de partes y de lugares se funda en un reparto de espacios, de tiempos y de formas de actividad que determina la manera misma en que un común se ofrece a la participación y donde los unos y los otros tienen parte en este reparto" (2009: 9).
} 
deambular por sus parajes a personajes nuevos, a quienes estaba vedado el espacio literario. Tanto Roberto Hozven como Claudia Darrigrandi ${ }^{5}$ han insistido en sus estudios sobre la novela en la emergencia de personajes como el roto que ingresan a la literatura a partir de las representaciones de la ciudad de un Santiago moderno cuya contracara está simbolizada por ciertos escenarios y figuras. En una línea parecida, Jaime Concha analiza la configuración del mundo minero en los cuentos de Lillo, idea que será discutida al adentrarnos en la lectura de algunos relatos de Sub terra. La aproximación biopolítica gira un poco la perspectiva, en la medida en que la dimensión social privilegiada en los estudios comentados se enriquece al acentuar las corporalidades, sus inscripciones y exclusiones en la presente propuesta.

\section{Demarcaciones de lo común}

He dicho que el noventa por ciento de la población de Chile no es nada, Excelencia, o es una recua de animales, a quienes se les tiene deliberadamente en este estado de salvajismo por el torcido criterio de una oligarquía de ideas sociales rancias, que no es capaz de comprender su propia conveniencia. (Pinochet 2010: 6)

En un polémico texto de 1916, publicado bajo el nombre "Inquilinos en la hacienda de Su Excelencia", el periodista Tancredo Pinochet se dirige en una carta abierta a Juan Luis Sanfuentes, en tal entonces Presidente de la República de Chile. En un acto pionero de periodismo encubierto - al menos para estas latitudes- Tancredo Pinochet se disfraza de inquilino para recorrer las tierras en los alrededores de Talca, pertenecientes a Sanfuentes. Busca trabajo como peón en una de las haciendas del Presidente en pos de poder vivenciar desde "adentro" el trato que reciben los campesinos. El texto, que da cuenta de este experimento social, arranca con un acto de travestismo; de periodista a peón, de rico a pobre, que se irá develando en el transcurso de la carta como una transformación más elemental: la de hombre a bestia. Lo que Tancredo Pinochet denuncia no es simplemente la brecha social que separa a la elite del pueblo, sino algo más dramático: la denigración de una gran parte de la población a una categoría de lo infrahumano. Más cercanos a los animales, los peones son tratados en tanto seres pertenecientes a una clase en la que lo humano se difumina, mostrando sus lindes con lo bestial. Ni siquiera es posible hablar de desprecio por parte de los terratenientes, pues la mirada de los dueńos de las posesiones y de aquellos que en su nombre actúan y dan trato a los inquilinos, conforman una comunidad que se autodefine en exclusión de aquello que taxonómicamente pareciera pertenecer a otra clase. El experimento realizado por Tancredo Pinochet es la transición de lo humano a lo no humano; lo que el texto designa como infrahumano, animal, bestial; esta raza esclava,

\footnotetext{
${ }^{5}$ Véase el capítulo dedicado a la novela El roto en Huellas en la ciudad de Claudia Darrigrandi y su artículo "Gente que uno ve pasar sin dejar huella" (2015b), así como el artículo "La ciudad de Santiago en el sentir de Joaquín Edwards Bello y de Jorge Edwards" de Roberto Hozven (2006), cuya discusión retomaremos más adelante en este artículo.
} 
estos sub-hombres representan el punto liminal desde donde la clase privilegiada define la comunidad nacional. Tancredo Pinochet, al disfrazarse de peón, ejecuta una mutación que implica el tránsito del bios a la zoé, para retomar esta distinción griega que separa la forma de vivir de un individuo o de un grupo con inscripción política, del simple hecho de la vida, común a humanos, dioses y animales.

Para las discusiones biopolíticas contemporáneas, tanto de Roberto Esposito (2009) como de Giorgio Agamben (2006), la referencia y discusión de esta distinción entre lo que este último llama vida calificada, por un lado, y vida nuda, por el otro, es de gran relevancia teórica. Para los dos filósofos el regreso a esta diferenciación griega implica una pregunta por el estatuto de la biopolítica en su relación con la modernidad. Para quien es considerado el pensador contem poráneo que activa el debate en torno a la biopolítica, Michel Foucault, esta es inminentemente moderna y hay un lazo estrecho entre biopoder y modernidad. Agamben y Esposito discuten esta ligazón. Las preguntas se dirigen precisamente a la comprensión de la vinculación entre biopolítica y modernidad. ¿Es la administración biopolítica de los cuerpos el hito que marca la entrada a un imaginario eminentemente moderno? ¿Son modernidad y biopolítica procesos paralelos que no necesariamente se implican mutuamente? ¿Es la biopolítica más antigua que la modernidad y estaría ya presente en cualquier pensamiento político que implica la concepción de una comunidad?

Agamben debate en Homo sacer el lugar privilegiado que Foucault otorga a la biopolítica como hecho decisivo para el ingreso a la modernidad, planteando que "las implicaciones de la nuda vida en la esfera política constituyen el núcleo originario -aunque oculto- del poder soberano. Se puede decir, incluso, que la producción de un cuerpo biopolítico es la aportación original del poder soberano" (Agamben 2006: 14). Para Foucault, el bipoder sustituye en la modernidad al poder soberano, que, como plantea en su Voluntad de saber, es un poder que se ejerce sobre la muerte y se expresa en el "derecho de matar": "El soberano no ejerce su derecho sobre la vida sino poniendo en acción su derecho de matar, o reteniéndolo; no indica su poder sobre la vida sino en virtud de la muerte que puede exigir" (Foucault 2009: 164). El argumento que introduce Agamben para disolver el vínculo necesario que Foucault postula entre el poder expresado bipolíticamente con el imaginario moderno, es que los inicios de la vida política en Occidente siempre ya implican una diferencia exclusiva con relación a la vida nuda. Esta consideración, de la zoé como aquello que queda excluido, es de corte eminentemente biopolítica: "La nuda vida tiene, en la política occidental, el singular privilegio de ser aquello sobre cuya exclusión se funda la ciudad de los hombres" (Agamben 2006: 17). El acto político en sí, que circunscribe una comunidad con limitación a aquello que queda fuera, implica un gesto biopolítico para Agamben. Un punto de central importancia en su argumentación es que la nuda vida no es necesariamente la de un otro que queda excluido de la comunidad, sino es, y quizás en primerísimos términos, la propia nuda vida que en nombre de la comunidad política se excluye: "Hay política porque el hombre es el ser vivo que, en el lenguaje, separa la propia nuda vida y la opone a sí mismo, y, al mismo tiempo, se mantiene en relación con ella en una exclusión inclusiva" (2006: 18). 
Esta idea me parece de gran relevancia para el análisis del corpus considerado aquí. Es decir, cuando los textos literarios reflexionan y debaten acerca de la pregunta sobre la comunidad, también comienzan a asomar ciertas cuestiones que tienen que ver con la corporalidad. No solo sobre los cuerpos otros, sino más bien sobre la dimensión de lo corporal. Volveré a este punto más adelante, pues aquí, a mi entender, se pueden apreciar las contradicciones y las tensiones que la asunción del imaginario moderno pareciera implicar para una serie de escritores chilenos tanto de finales del siglo XIX como de comienzos del XX.

Lo que Agamben acentúa en tanto arista propiamente moderna de la biopolítica es que "se presenta desde el principio como una reivindicación y una liberación de la zoé [...] trata[ndo] constantemente de transformar la nuda vida misma en una forma de vida y de encontrar, por así decirlo el bíos de la zoé" (2006: 19). Es este el ademán que reconocemos en el texto de Tancredo Pinochet. Lo que acusa su carta es que desde las clases dominantes, la categoría de lo vital -zoé- es sometida a una distinción política que separa la vida ciudadana de otra percibida en tanto mera vida animal, sin asociación a lo ciudadano ni político. La vida queda, de este modo, definida a partir de una subdivisión en dos categorías: una que comprende una comunidad que permite una enunciación identitaria, y otra que queda marginada de esta colectividad. Volviendo al travestismo del que arranca el texto de Tancredo Pinochet, este envuelve, entonces, un tránsito taxonómico y axiológico, y lo que pretende denunciar la carta es precisamente el corte realizado por este límite. Podríamos decir que el periodista está exigiendo un traslado, una redefinición del margen de aquello que queda incluido y aquello excluido por el trazado de los límites. El marco del bios debe abrirse y dibujarse con criterios que permitan la entrada de una gran parte de la población chilena hasta ahora posicionada en la zoé. Tancredo Pinochet se dirige con esta demanda al Presidente de la República: "No os habla un periodista. Os habla Chile rural, Excelencia, y os habla en un momento supremo en que hay que tomar resoluciones supremas" (2010: 18).

Esta resolución demandada tiene que ver con un cambio en la concepción del bios, involucrando una transformación de lo común y la comunidad. Esposito, quien ha desarrollado su teoría biopolítica en torno a la noción de inmunidad, ha insistido en ella en tanto contracara de la comunidad, que "aparece como una cualidad, un atributo, que se ańade a uno o más sujetos convirtiéndoles en algo más que simples sujetos, en tanto radicados en -o producidos por- su esencia común" (Esposito 2009: 15). Tancredo Pinochet precisamente insiste en este común; el acto de travestismo involucra un disfraz que debajo esconde no la diferencia sino la comunidad: "Os habla Chile rural". Surge una voz colectiva vehiculada por esta búsqueda de lo común, que debe borrar cualquier distinción, que adquiere el carácter de arbitraria y circunstancial, mas no fundamental. En palabras de Esposito: "El resultado es que se remite a la comunidad a la figura del proprium: se trata de comunicar cuanto es común o propio, de modo que la comunidad queda definida por las mismas propiedades -territoriales, étnicas, lingüísticas- que sus miembros. Éstos tienen en común su carácter de propio y son propietarios de aquello que es su común” (2009: 15).

Con su texto, Tancredo Pinochet se une a una serie de voces que a partir de fines del siglo XIX y en las primeras décadas del XX denuncian, desde la política, la prensa, las letras, 
las injusticias vividas a partir de la gran brecha que separa a la elite económica y política del pueblo. La "cuestión social" se debate transversalmente en problemáticas vinculadas a la organización urbana, la vivienda, la salud pública, la educación. La problemática habitacional y las deficientes condiciones sanitarias se posicionan en el centro de las preocupaciones públicas, implicándose con ello una discusión en torno al futuro de la raza. Presunciones eugenésicas se entrecruzan con teorías de la degeneración, aproximaciones socialdarwinistas, perspectivas urbanísticas, planes de higiene social y anhelos medicalizadores. En 1889 se crea el Consejo de Higiene bajo el gobierno de Balmaceda, constituido a partir de la necesidad de organizar una institución estatal para dirigir una política nacional de salud con el fin de combatir las epidemias mediante la prevención sanitaria de toda la población. Las epidemias de la viruela y el cólera, la endemia de fiebre tifoidea y tuberculosis, así como las afecciones venéreas, especialmente la sífilis, seguían con índices de mortalidad muy altos, en gran medida debido a las miserables condiciones sanitarias, producto de la situación habitacional. En las últimas décadas del siglo XIX se evidencian los primeros intentos de delimitar y combatir el problema, buscando la autoridad pública segregar territorialmente las zonas "peligrosas" y mórbidas de aquellas cultas y sanas. En 1872, Vicuña Mackenna -el Haussmann chileno- propone un programa urbanístico, estableciendo un "cordón sanitario", para deslindar la "culta capital de Chile", que él designa "Santiago Propio", de las "influencias pestilenciales de los arrabales". La así llamada Chimba contiene todos los males sociales, percibidos en tanto propiedades de una masa informe en la que se superpone alcoholismo, prostitución, enfermedad vicio y amoralidad. Más que individuos acechados por una patología o destino personal, los pobres son una aglomeración de todo aquello que peligra la constitución de la civilidad. El concepto de sociabilidad manejado por la elite desde el siglo XIX se vehicula a través de los anhelos modernizadores y el deseo de creciente progreso. Si en los discursos del diecinueve las clases menos privilegiadas apenas se asoman en el campo visual de quienes elaboran los grandes proyectos nacionales, pensados desde el liberalismo ilustrado, a partir de fines del siglo XIX irrumpen la pobreza, la injusticia, la explotación en la mirada pública.

Lo que me interesa revisar es qué es lo que se percibe que irrumpe ahí. ¿Desde dónde se mira y considera esta "otredad" que va apareciendo en textos de diversa índole, incluyendo el ámbito literario, a partir del cambio de siglo? ¿Qué contradicciones se manifiestan en estas distintas perspectivas que piensan a este "otro"? Y cómo las categorías ahí ensayadas ostentan los signos de una modernidad vivenciada en tanto contradicción:

\footnotetext{
${ }^{6}$ Del siguiente panorama dibujado por María Elena Muñoz puede inferirse de manera muy clara cómo el plan urbanístico de Vicuña Mackenna pretende una doble impronta que se dirige, por un lado, a la organización arquitectónica y urbana de la ciudad y, por el otro, a la administración de los cuerpos que la habitan: "La apropiación del modelo francés por parte de Vicuña, en nombre de le élite ilustrada, pretendía convertir a la capital chilena en el París americano; es decir, en una ciudad modelo para otras en el mismo territorio e incluso en el continente, un ejemplo que más que solo incidir en la mera distribución de los espacios ambicionaba constituirse en una estrategia civilizatoria capaz de borrar los signos visibles de la barbarie, encarnada en los resabios coloniales y en la persistencia de la ignorancia, la insalubridad y la miseria” (2014: 9).
} 
como promesa de justicia y bienestar, por un lado, y como violencia que coarta libertad e individualidad, por el otro. Lo que quisiera postular es que todas las variantes de ver y pensar al "otro" redundan en que en el límite que lo separa y distingue se juega la idea de comunidad, de un nosotros que configura una colectividad política e identitaria: tanto para un nosotros que ignora al otro, como para quienes acusan esta ignorancia con la intención de ampliar la comunidad e integrar al otro, como también para una visión donde el otro contiene una fuerza inadministrable para la comunidad, que puede valorarse tanto de manera positiva como negativa. A partir de esta primera premisa, quisiera plantear una segunda. Si lo que está puesto sobre el tapete es el asunto de la comunidad, la definición de lo propio en relación a lo otro, también estaría en tensión la definición de vida humana. Es decir, la distinción entre bios y zoé, la vida atravesada políticamente y generadora de lo común, y una que taxonómica y valóricamente queda situada en un lugar distinto.

Volviendo a Tancredo Pinochet: lo que el periodista balmacedista, nacionalista de tomo y lomo, y convencido pedagogo del progreso, pretende lograr con la carta que dirige retóricamente al Presidente, es generar conciencia respecto a la exclusión fundamental realizada por la elite. Tancredo Pinochet ostenta la forma en que opera una distinción primordial en la población chilena organizadora de una comunidad conformada por un bios que se deslinda de una vida entendida en tanto indigna de formar parte de ese colectivo, capaz de constituirse en ente político. Esta diferencia -de clase no solo en el sentido social sino también ontológico- proviene de la organización social oligárquica decimonónica. La elite ilustrada del diecinueve, que sienta las bases ideológicas y fácticas del estado-nación chileno, funde en el anonimato a las grandes masas poblacionales, constituyendo un mundo de las luces ilustradas tan solo para una elite minoritaria. Discursos escritos por la elite, que se hacen cargo de problemas de esa elite, y dirigidos y leídos por un público igualmente perteneciente a la elite; las letras, la literatura, la política son actividades que se restringen a un pequeño reducto de la población que habita el país. Recién a fines del siglo XIX, esta invisibilización por parte de la intelectualidad decimonónica emerge en los discursos letrados, en parte por una paulatina transformación producida por la profesionalización del campo intelectual que permite a autores no oligárquicos hacerse espacio en este mundo antańo reservado a los poderosos. Tancredo Pinochet es un ejemplo de ello, así como también otros escritores en los cuales leemos demandas sociales parecidas: Baldomero Lillo, que se sumerge Sub terra y Sub sole para denunciar las miserables condiciones de vida y esclavizantes circunstancias laborales de los mineros de Lota y Coronel, abundando también aquí las comparaciones con animales y bestias; o Augusto d'Halmar, quien escribiera la historia de la huacha más emblemática de las letras chilenas: su Juana Lucero, cuyo camino de degradación y decadencia, material, físico y moral escribe la historia de y sobre un cuerpo doliente, que lleva las marcas de sus continuas exclusiones.

El punto de arranque de las obras comentadas acá es, entonces, esa misma distinción radical entre una vida entendida en tanto constituyente de lo común, y una situada fuera de la comunidad. Lo que se transforma y eso de forma importantísima, es, por un lado, la visibilización del límite, antes presupuesto en tanto esencial y natural, por lo tanto, indigno 
de ser comentado; $y$, por el otro, la impronta valórica, que denuncia este límite como injusto $y$, en consecuencia, necesario de mover y trazar de otra forma.

\section{UNA MODERNIDAD CON CABEZA DE JANO:}

“-¿Pobre viejo, te echan porque ya no sirves! Lo mismo nos pasa a todos. Allí abajo no se hace distinción entre el hombre y las bestias. Agotadas las fuerzas, la mina nos arroja como la arańa arroja fuera de su tela el cuerpo exangüe de la mosca que le sirvió de alimento" (Lillo 2008: 92), relata el narrador de "Los inválidos", uno de los cuentos incluidos en Sub terra de Baldomero Lillo. El cosmos de la mina, situado no solo físicamente debajo del mundo que ostenta la faz moderna del Chile de comienzos del siglo XX, se revela en tanto inframundo, donde lo humano pierde sus contornos identitarios. Las narraciones de Lillo insisten, una y otra vez, en las comparaciones animalescas: hombre y bestia se confunden hasta hacerse indistinguibles. La vida humana se reduce a una existencia vital cuyas fuerzas se agotan en el trabajo extenuante de la mina. Comenta Jaime Concha acerca de "Los inválidos": "El código estético y estilísticos del naturalismo le suministran sus instrumentos expresivos más característicos y su énfasis en la visión de la vida como materia degradada y carne carcomida por fuerzas destructoras" (2008: 58).

Debajo de la tierra, sumidos en la invisibilidad para todo quien no quiera ver, alejados de las luces, tanto del sol como de las luces ilustradas, supuesto garante del saber y de la libertad, los hombres-bestias de Lillo representan la contracara de la modernidad: su talante oculto, pero también su condición de posibilidad ${ }^{7}$. La explotación de una parte de la población reducida a vida nuda -en palabras de Agamben-, vitalidad al servicio de la fuerza de producción, parece requerirse para el funcionamiento de la máquina industrializadora. El minero es debajo de la tierra lo que las líneas de tren son sobre la geografía dominada: imágenes inversamente reflejas de una modernidad que promete la entrada al progreso al mismo tiempo que cobra violentamente su precio $^{8}$.

\footnotetext{
${ }^{7}$ Jaime Concha plantea, en su prólogo a la Obra completa, una serie de elementos importantes para releer a Baldomero Lillo. Retoma allí las ideas de un historiador de la tecnología, Lewis Mumford, que diferencia tres etapas en la historia de las técnicas de los seres humanos, según la fuente de energía ocupada. La eotécnicacorrespondiente principalmente al mundo antiguo y la Edad Media, que usaba las energías naturales del agua y el viento-, la paleotécnica -que ocupaba sobre todo hierro y carbón- y la neotécnica, referente al mundo contemporáneo en el cual domina el plástico. Baldomero Lillo estaría situado en pleno auge de la era paleotécnica, que encuentra su emblema más paradigmático en el tren. La velocidad del tren que domina las distancias con su fuerza, tiene su lado oscuro en el mundo subterráneo de la mina. Escribe Concha: "el carbón cumple entonces un papel decisivo durante el período paleotécnico que corresponde, en otra terminología, a lo que el viejo Toynbee y, antes que él, Marx, Engels, Stuart Mill y otros llamaron Revolución Industrial” (2008: 34).

${ }^{8}$ En esta perspectiva, muchos de los cuentos de Lillo reiteran temáticas centrales para la literatura de las primeras décadas del siglo XX. En un artículo que explora las relaciones entre lectura, proletariado y pobreza, Claudia Darrigrandi describe una escena de lectura contenida en Los hombres oscuros de Nicomedes Guzmán, novela de 1939, en la que un personaje proletario lee una serie de textos, entre otros a Baldomero Lillo, que le son prestados
} 
En "El Pago", un minero explotado brutalmente por un sistema injusto de cobranzas que confisca todo su sueldo, tiene un sueño visionario que muestra la conformación dialéctica de esta modernidad:

Al contacto del oro la tierra se estremecía y como al golpe de una varilla mágica, brotaban de su seno palacios y moradas espléndidas en cuya estancias resplandecientes como el día, innumerables parejas se entrelazaban al acompasado son de voluptuosas danzas. De pronto los bailes y las músicas cesaron y una luz extraña, rarísima, iluminó los aposentos. Los diamantes que brillaban en los cabellos y gargantas de las mujeres se desprendieron de sus engarces y rodaron como lágrimas por los níveos hombros y senos de las hermosas, haciéndolas estremecerse con su húmedo contacto. Los rubíes dejaban al caer manchas sangrientas sobre los regios tapices. Y las paredes, las escalinatas, los bronces y los mármoles, tomando un tinte rojo, violáceo, horrible, parecían de sangre coagulada (Lillo 2008: 74).

Aparente aporía de una modernidad que se revela en su duplicidad, esta imagen onírica es significativa para postular las maneras propias de asunción del imaginario moderno en Chile. Es el sueño moderno, que se revela en tanto pesadilla de lo moderno: uno se transforma en el otro, sueño como anhelo y deseo, y sueño en tanto mundo gobernado por fuerzas oscuras que emergen atravesando el afán de progreso.

Llamativo es en la cita de más arriba que recuerda en su imaginería y lenguaje al modernismo literario, si bien, naturalismo y modernismo muchas veces han sido leídos como movimientos más disímiles que semejantes. Como bien plantea Sabine Schlickers en su estudio sobre la narrativa naturalista en Hispanoamérica, "la corriente naturalista tardía y la finisecular resultan mucho menos distintas de lo que sus representantes suponían en aquel entonces" (2003: 382). Al modernismo se le presume un expreso anti-modernismo, mientras que al naturalismo se le suele atribuir más bien una ideología acorde al progreso moderno. Sin embargo, también en muchas obras que se leen desde la estética naturalista, puede reconocerse un "inventario ficcional desilusionado de los fenómenos sociales y culturales de la difícil modernidad" (Schlickers 2003: 383). Sin lugar a dudas, que los cuentos de Baldomero Lillo participan de una visión crítica frente a los procesos modernizadores, que correspondería a una "vertiente materialista que critica las fallas sociales y morales del progreso económico" (Schlickers 2003: 383).

Otra novela emblemática para evidenciar las contradicciones que el imaginario moderno suscitó en muchos escritores e intelectuales de estas latitudes, es la novela El roto de Joaquín Edwards Bello, gran cronista de la época, más allá de su novelística. En ella construye imágenes aberrantes de la miseria vivida en los aledaños a la Estación Central,

por su amigo gremialista. Comenta Darrigrandi las lecturas y el vínculo con la obra del propio Guzmán: "Estos tres libros de ficción [Huxley, Lawrence, Lillo], en su conjunto dan cuenta de los procesos de industrialización, la condición obrera, la explotación, la deshumanización del hombre, la relación entre instinto y razón, entre otros tópicos que también están presentes en la novela de Guzmán” (2017: 143). 
emblema ferroviario celebratorio de los avances técnicos y el progreso económico en el Chile del Centenario:

Acurrucados en el suelo, parecen acechar; uno es tuerto; otro tiene en lugar de la nariz un agujero siniestro, revelador del mal que pudre sus carnes; el de más allá, de quince años, está consumido por la peste blanca; otro, el gordo, se presta al vicio inenarrable y no se ruboriza cuando le llaman con los nombres más degradantes; aquél, blanco, alto, de rostro lívido, es un asesino que la policía persigue (Edwards Bello 2006: 21).

En esta galería del horror, donde se funde la enfermedad, el vicio, la amoralidad y el crimen, nuevamente germina una narrativa que conforma un cuerpo colectivo de mera existencia material. Las diferencias políticas propias de la sociabilidad, que permiten un vínculo armónico entre el individuo y la colectividad que integra, están acá ausentes: indistinta masa uniforme, zoé pura, indiferente en el sentido de la ausencia de diferencias que marcan lo propio, pero también en tanto insignificante. Una insignificancia que, como planteado más arriba, es significativa, pues traza el límite entre lo inteligible en términos de civilidad y aquello que se posiciona como vida previa a sus inscripciones políticas. Y, simultáneamente conformando una distinción biopolítica fundamental: una que separa la vida que vale la pena ser vivida y aquella dispensable.

El roto está colmado de escenas como la evocada en la cita, referentes a la vida miserable en los conventillos y prostíbulos lindantes a la Estación Central-la férrea estructura de la estación de trenes se sitúa en proximidad a su contracara: la pobreza deshumanizante. Como bien destaca Roberto Hozven en su lectura de la novela: "La Estación Central y su entorno personifican la etopeya de los habitantes de Santiago: un centro moderno en movimiento progresista contrapuesto, por detrás, contra la barriada sórdida de la cual la estación emerge sin terminar de despegarse (Hozven 2006: 6)". ${ }^{9}$ En este sentido, vemos repetido el gesto de una literatura, tal como en la carta abierta de Tancredo Pinochet y en los cuentos de Baldomero Lillo, que utiliza el texto en tanto plataforma de acusación y reivindicación ${ }^{10}$. Lo que se evidencia es que los pobres, más similares a los animales que

${ }^{9}$ En su artículo sobre El roto, Hozven explora tanto simbólica, geográfica e históricamente la imagen de la
Estación Central, estación que comunicaba los trenes entre Santiago y Valparaíso, funcionando al mismo
tiempo como un eje urbano y social dentro de la misma capital. A partir de la lectura de la novela de Joaquín
Edwards Bello, añadiendo también su trabajo cronístico en el análisis, Hozven se hace la pregunta por qué tipo
de comunidad nacional estaría figurada en la obra de Edwards Bello (Hozven 2006).
${ }^{10}$ Un pasaje de la novela incluye estadísticas acerca de las así llamadas enfermedades sociales que acechan a la
ciudadanía santiaguina de la época: "Las estadísticas espantan: en siete ańos, la viruela consume más de 30.000
chilenos y la tuberculosis, en sus diversas manifestaciones, más de 60.000 . La sífilis hace estragos mayores. En
1908, las policías de la República recogen por las calles y caminos 58.000 ebrios; en 1911 recogen ¡130.000!
[... . El Mercurio de Santiago del 20 de junio de 1914 , hacía pública una estadística espantosa sobre cárceles de
la nación; en 1905 se habían indultado 144 reos y se habían evadido 180 ; en 1907 y 1908 el número de reos 
a los humanos, enfermos, explotados, marginados e ignorados, parecieran reclamar una representación literaria antaño negada, y que esta aparición simbólica implica una necesaria redefinición de los límites de la comunidad nacional. Esta, así el subtexto político, debe abrir sus fronteras para hacer ingresar a una gran mayoría de la población situada en sus confines.

Sin embargo, y he aquí una diferencia de El roto con relación a los otras obras analizadas, a su vez el lector encontrará imágenes de la otredad que, igualmente esencializantes, la romantizan ${ }^{11}$. En las obras de Joaquín Edwards Bello y especialmente en El roto puede ser reconocida una figuración ambigua de los personajes del roto y de la prostituta: si bien se animalizan y embrutecen por sus biografías marcadas por la pobreza, la dureza de la vida y la constante lucha por la supervivencia, por el otro lado, se dibujan como fuerzas caracterizadas por un impulso irrefrenable. Muchas veces esta fuerza no se traduce en posibles proyectos de vida canalizables en caminos con destino y finalidad, pero sí como energía pura, celebrada justamente en su ausencia de direccionalidad y fin. Roto, prostituta, criminal: las figuras que se construyen detrás de la Estación Central y de espaladas a la modernidad, condicionándola al mismo tiempo, se vuelven símbolos de una libertad sin concesiones, de una particularidad irreductible por la máquina homogeneizadora de industrialización y modernidad. La calle, con su anonimato, su propio set de reglas que rivaliza con el establecimiento de la ley, con su libido fluyente constituyen una constante amenaza a los planes de regulación moderna. El roto desafía las normativas burguesas, los ordenamientos urbanos de la ciudad moderna, las definiciones identitarias del sujeto establecidas por las dos grandes instituciones normalizadoras de la modernidad: la medicina y el derecho. La formación del roto se va generando en la medida en que la individualidad se funde con la masa informe de una materialidad que abarca lo que se aglomera en los márgenes de la ciudad letrada, constituyendo su propia ley. Esta posibilidad se somete, en el texto de Edwards Bello, a una idealización romántica: una que pasa por articularse en el límite al bios, a la comunidad, a la definición política de lo individual y su relación con lo colectivo. El roto y la prostituta, figuras complementarias en la novela de Edwards Bello, encarnan un punto de fuga de la administración racional de los cuerpos en la modernidad ${ }^{12}$.

evadidos era asimismo superior al de indultados. En 1907, indultados: 103, evadidos: 102, en 1908 indultados: 154, evadidos 212..." (Edwards Bello 2006: 27-28).

${ }^{11}$ Sin querer impulsar una lectura autobiográfica de las obras, sí podría tener que ver en esta diferencia la extracción social del propio Joaquín Edwards Bello. Reuniendo en su nombre dos ilustres apellidos de importancia cultural y económica en Chile, Edwards Bello hace emerger ya en sus primeras incursiones novelescas una cierta fascinación por las clases más bajas. Asiduo a prostíbulos y ludópata, Edwards Bello en muchos de sus textos articula una visión ambigua con relación a las clases menos privilegiadas. Por un lado, tal como en El roto, el ser humano se bestializa y embrutece en la pobreza, pero, por el otro lado, también hay un aire libertario en la pobreza que no está restringida por las estrictas amarras de etiqueta que las clases de elite ostentan en tanto signo de distinción. Algunas coordenadas de esta especie de "abajismo" social de Edwards Bello están trabajadas en el artículo de Andrea Kottow, "Machos, lachos, padres e hijos en la obra de Joaquín Edwards Bello" (2009).

${ }^{12}$ Michel Foucault, en La vida de los hombres infames, recorre en uno de sus capítulos la genealogía de la medicalización en Europa, identificando tres líneas fundamentales para su cristalización. En primer lugar, 
Una sexualidad que se escabulle al llamado de la procreación, una vagancia que se escapa a la imposición de la productividad: prostituta y roto son cuerpos que no se dejan gobernar por el aparato moderno. Son cuerpos que se resisten, aunque las consecuencias de su resistencia sean, en definitiva, un puro gesto de irreverencia. Cuando Esmeraldo, el nińo protagonista de la novela de Edwards Bello, se fuga de su "protector" ilustrado para volver a las calles, siente una sensación de felicidad que el texto acoge sin condena:

Contempló la calle con interés profundo. Vio a lo lejos, cerrado, el puesto de las Varona, las Venus pandemus, famosas entre esos rotos de estómago férreo y cuero duro. Recordó a la gorda de ojos verdes y a la Rebeca, alta y esbelta, con su cuello derechito. Amaba aquello, le gustaba todo aquello; sentíase dispuesto a fraternizar con ese mundo dado a la lujuria y la crápula; una racha eléctrica le venía por el cuerpo al sentimiento de su libertad. (Edwards Bello 2006: 154)

Contrasta la narración realizada desde la perspectiva de Esmeraldo, donde los rotos anónimos son bautizados y destacados en sus fortalezas y bellezas ${ }^{13}$, con la cita de más arriba, configurada desde la mirada de un narrador naturalista, que no es capaz de distinguir subjetividades en la materia viva. Lo que Edwards Bello ostenta, en la lectura propuesta, es una forma contradictoria de vivir la modernidad, o incluso más, las contradicciones de la propia modernidad. Pues no parece considerar que estas resistencias forman parte, a su vez, del mismo sistema biopolítico al que aparentemente burlan. Es decir, es el discurso letrado que incide en el "cuerpo pobre" de tal manera que este recién se configura. Sea como animal o bestia, sea como pobre digno de formar parte de la comunidad, o sea en tanto energía libidinal, pura pulsión de vida, que termina por destruirse a sí misma. El texto se abre al resto de una contradicción no conciliable. De este modo, y como plantea Gabriel Giorgi:

\footnotetext{
la medicina de estado, desarrollada principalmente en Alemania, en segundo lugar, la así llamada medicina urbana, circunscrita sobre todo a partir del escenario francés, y en tercer lugar, la medicina de la fuerza laboral en Inglaterra. Para este tercer caso, Foucault destaca que desde su creación puede observarse una "resistencia popular" (2006: 103) que intenta escabullir al control médico. Para Foucault se trata de "grupos disidentes de diversos tipo en los distintos países, cuya finalidad era combatir la medicalización, reivindicar el derecho a la vida, el derecho a enfermarse, a curarse y a morir, según el deseo propio" (2006: 103). No quiero sugerir que Edwards Bello está haciendo una descripción históricamente fidedigna de este tipo de actitudes de insurrección, pero sí pienso que hay una romantización, quizás incluso en el mismo Foucault, de ciertas fuerzas supuestamente opuestas a la homogenización moderna. Esta representación de los pobres les otorga un lugar particular dentro de la representación social, donde es equiparado con cierta autenticidad, pureza y falta de concesión.

${ }^{13}$ La figura del roto se presta desde el siglo XIX -ejemplarmente en raza chilena de Nicolás Palacios- para idealizar un cierto tipo de hombre marcadamente viril. También en El roto de Edwards Bello están presente estas imágenes de un hombre fuerte, masculino, valiente y guerrero, que remite a la idealización del roto a partir de su participación en la Guerra del Pacífico. Claudio Véliz Rojas rastrea las vinculaciones de la configuración del roto y el nacionalismo en la obra bajo la tienda de Daniel Riquelme (Véliz Rojas 2015).
} 
Entre el hacer vivir y el umbral móvil de la zoé se traza así un paisaje u horizonte complejo, proliferante, de gradaciones y ambivalencias entre cuerpos y entre modos del vivir y del morir; cuerpos que expresan la plenitud de lo viviente y la norma de la potencia colectiva frente a otros que, en cambio, trazan el umbral de la nopersona, el muerto-vivo, del espectro, o de la vida reducida a su expresión mínima, la vida que se puede consumir, explotar, constituir en cosa viviente, etc. (2014: 26)

La cita de Giorgi le otorga un lugar de reflexión no resolutiva a la literatura y al arte que me parece decidor para el análisis de los textos que hemos comentado. A pesar de que en muchos casos se trata de obras con fines de reivindicación social, a su vez, los análisis van develando las contradicciones, los espacios intermedios, las tensiones que colman a las narrativas. Como afirma más adelante Giorgi acerca de los discursos e imágenes literarias y artísticas, se trataría de "un laboratorio de los modos de ver, de percibir, de afectar los cuerpos donde se elaboran otros regímenes de luz y de sensibilidad que hacen a otra comprensión de lo que es un cuerpo, lo que puede y, sobre todo, de lo que pasa entre cuerpos" (Giorgi 2014: 43). Es decir, de un espacio de experimentación y experiencia, de un espacio en el cual se posibilita experimentar con la experiencia.

Quisiera, finalmente, retomar algunos planteamientos expuestos por Judith Butler en su libro Cuerpos que importan, que inspiró el título de este análisis. En su prefacio, Butler señala una dificultad que emerge al poner los intereses investigativos en la teorización del cuerpo: "Los cuerpos no sólo tienden a indicar un mundo que está más allá de ellos mismos; ese movimiento que supera sus propios límites, un movimiento fronterizo en sí mismo, parece ser imprescindible para establecer lo que los cuerpos 'son'” (Butler 2015: 11). Tomando esto como punto angular de cualquier posible análisis, Butler luego empuja la argumentación a la tarea analítica de concebir las significaciones de las construcciones corporales. Si bien el horizonte de Butler es el cuerpo sexualizado y genéricamente constituido, su razonamiento puede servir para enfocar lo que he estado arguyendo acá: las inscripciones biopolíticas que producen los cuerpos, disponen esferas de cuerpos inteligibles, pero también "un dominio de cuerpos impensables, abyectos, invivibles" (2015: 14). Este campo de la abyección, si bien no cumple con los requisitos para conformar un "sujeto", forma un afuera constitutivo para aquello de lo que queda excluido. En este sentido, los textos que hemos ido revisando no solo hablan de los pobres o los enfermos como aquella zoé no clasificada políticamente, sino, y en gran medida, por contraste evidencian los atributos del bios, de aquellos cuerpos que sí conforman una vida relevante y legible. Tal como una donut, su centro es vacío pero organizador de lo que lo rodea, que sería materialidad pura, masa informe. Solo el centro permite que "eso", que queda por fuera, pueda reconocerse. Butler escribe: "En este sentido, pues, el sujeto se constituye a través de la fuerza de la exclusión y la abyección, una fuerza que produce un exterior constitutivo del sujeto, un exterior abyecto que, después de todo, es 'interior' al sujeto como su propio repudio fundacional” (2015: 20). Lo que Butler plantea para el sujeto, puede extenderse al cuerpo nacional, donde el mito fundacional genera sus limitaciones exteriores dejando en su centro el vacío de la propiedad. En este sentido, y 
así como enunciado más arriba, la propia corporalidad y el lugar que ocupa para el sujeto moderno reiteran los movimientos de la comunidad con relación a lo excluido de ella.

\section{A MOdo de CONCLusión:}

Como bien ha destacado Agamben, la particularidad de la biopolítica moderna, y es ahí donde coinciden los pensamientos de Foucault, Esposito y Agamben, es la inclusión de la zoé en consideraciones políticas. La exclusión como inclusión, la ignorancia como significación, la acusación como administración, la romantización como nueva exclusión: hemos propuesto revisar algunos de los movimientos realizados por diversos textos de comienzos del siglo XX, escritos en el horizonte de lo moderno, para mostrar de qué forma piensan la comunidad, siempre ya política, y lo humano, en tanto supuesta distinción anterior que recién posibilitaría la diferencia política. La vida nuda, como la ha llamado Agamben, se atraviesa políticamente en el momento de ser pensada en relación a la comunidad política que la define: en las miradas ilustradas del siglo XIX, es una población informe con respecto a la cual la ciudad letrada se constituye. En textos de denuncia, como el de Tancredo Pinochet, se acusa este límite, se visibiliza, evidenciando la diferencia radical que establece entre una vida entendida en términos comunitarios y una que queda marginada y situada en proximidad a la vida bestial, animal, inhumana. En los cuentos de Lillo vemos repetirse este mismo mecanismo, si bien parece ya hacerse evidente la inmersión en la dialéctica propia de la modernidad. Asoma una fatalidad difícil de escabullir: las luces de la modernidad crean su necesaria sombra, que acecha y persigue. En El roto de Edwards Bello, los cuerpos de enfermos, pobres y prostitutas vuelven a servir de superficie de imputación de exclusiones injustas; sin embargo, aporéticamente, terminan por excluirse a través de un dispositivo que idealizando margina: la exclusión se vuelve inclusión.

Para finalizar este mapa, provisorio e incompleto, de las formas que la otredad pobre y enferma adopta en algunos textos de comienzos del siglo XX en Chile, quisiera pensar el espacio literario como aquel que puede, de forma privilegiada y sin avergonzarse, ostentar las contradictorias maneras en que lo moderno se asoma en la joven nación. En esa dirección parece apuntar el llamado de Homi Bhabha cuando escribe: "Necesitamos otro tiempo de escritura, que pueda inscribir las intersecciones ambivalentes y quiasmáticas del tiempo y el espacio que constituyen la problemática experiencia 'moderna' de la nación occidental" (2007: 177). Esta escritura, como murmullo que acompaña a los grandes discursos políticos y oficiales defensores de la homogeneidad de la nación moderna, es la que asoma en los textos revisados, colmados de fisuras y pliegues, en los que nos encontramos oblicuamente con la experiencia de las contradicciones de la modernidad. 


\section{Obras CITADas}

Agamben, Giorgio. 2006. Homo sacer. El poder soberano y la nuda vida. Trad. Antonio Gimeno Cuspinera. Valencia: Pre-textos.

Bhabha, Homi K. 2007. El lugar de la cultura. Trad. César Aira. Buenos Aires: Manantial.

Butler, Judith. 2015. Cuerpos que importan. Sobre los limites materiales y discursivos del 'sexo'. Trad. Alcira Bixio. Buenos Aire: Paidós.

Concha, Jaime. 2008. Introducción. Baldomero Lillo. Obra completa. Eds. Ignacio Álvarez y Hugo Bello. Santiago de Chile: Ediciones Universidad Alberto Hurtado.

Darrigrandi, Claudia. 2015a. Huellas en la ciudad: Figuras urbanas en Buenos Aires y Santiago de Chile, 1880-1935. Santiago: Cuarto. Propio.

- - . 2015b. "Gente que uno ve pasar sin dejar huella: El Roto en las portadas de la novela de Joaquín Edwards Bello. Revista Iberoamericana. 81 (250). 73-94.

- - - 2017. "Lectura, proletariado y pobreza en Los hombres oscuros (1939) de Nicomedes Guzmán”. Revista de Humanidades, 35. 137-157.

Edwards Bello, Joaquín. 2006. El roto. Santiago de Chile: Editorial Universitaria.

Esposito, Roberto. 2009. Comunidad, inmunidad y biopolítica. Trad. Alicia García Ruiz. Barcelona: Herder.

Foucault, Michel. 2006. La vida de los hombres infames. Eds. y trads. Julia Varela y Fernando Alvarez-Uria. La Plata: Editorial Altamira.

- -. 2009. Historia de la sexualidad. 1. La voluntad de saber. Trad. Ulises Guiñazú. México, D.F.: siglo xxi editores.

Giorgi, Gabriel. 2014. Formas comunes. Animalidad, cultura, biopolitica. Buenos Aires: Eterna Cadencia Editora.

Hozven, Roberto. 2006. "La ciudad de Santiago en el sentir de Joaquín Edwards Bello y de Jorge Edwards". Revista chilena de literatura, 69. 5-23.

Kottow, Andrea. 2009. "Machos, lachos, padres e hijos en la obra de Joaquín Edwards Bello". Revista UDP. Pensamiento y cultura, 8. 134-145.

Legrás, Horacio. 2004. "Criollismo e Indigenismo literarios: representación sin resto y resto sin representación". Latin American Literatures: A Comparative History of Cultural Formations. Vol. 3. Ed. Mario Valdés, Linda Hutcheon y Djelal Kadir. Oxford: Oxford University Press.

Lillo, Baldomero. 2008. Obra completa. Eds. Ignacio Álvarez y Hugo Bello. Santiago de Chile: Ediciones Universidad Alberto Hurtado.

Muñoz M., María Elena. 2014. Atisbos de una experiencia. Pintura chilena y vida moderna, 1880-1930. Santiago de Chile: Ediciones Metales Pesados.

Pinochet, Tancredo. 2010. Inquilinos en la hacienda de Su Excelencia. Santiago de Chile: LOM Ediciones.

Rancière, Jacques. 2009. El reparto de lo sensible. Trad. Cristóbal, Durán et. al. Santiago de Chile: LOM Ediciones.

Romero, Luis Alberto. 2007. ¿Qué hacer con los pobres? Elites y sectores populares en 
Santiago de Chile. 1840-1895. Santiago de Chile: Ariadna Ediciones.

Schlickers, Sabine. 2003. El lado oscuro de la modernización: estudios sobre la novela naturalista hispanoamericana. Madrid/ Frankfurt am Main: Iberoamericana/Vervuert.

Sommer, Doris. 2004. Ficciones fundacionales. Las novelas nacionales de América Latina. Trad. José Leandro Urbina y Ángela Pérez. Bogotá: Fondo de Cultura Económica.

Subercaseaux, Bernardo. 2004. Historia de las ideas de la cultura en Chile. Tomo III. El centenario y las vanguardias. Santiago de Chile: Editorial Universitaria.

Véliz Rojas, Claudio. 2015. "Bajo la tienda (1959). La representación subalterna del "roto" como fundamento de nacionalidad para el siglo XX chileno. Diálogo Andino, 48. $7-17$. 